\title{
The Historical Origin of Changchun Green Space System Planning Molds City Characteristics
}

\author{
Liu Baochang ${ }^{1, *}$, Sha Xiangxiang ${ }^{1}$, Shi Yucheng ${ }^{1}$ \\ ${ }^{1}$ College of Architecture and Urban Planning, Changchun University of Architecture and Civil Engineering, \\ Changchun, Jilin, 130000, China \\ *Corresponding author's e-mail:84505170@qq.com.
}

\begin{abstract}
City characteristics is an important carrier to improve urban quality and inherit urban culture, and green space system planning can play an important role in shaping urban physical and geographical characteristics, urban cultural characteristics, urban artificial environment characteristics. Changchun City has its unique representative in this aspect. This paper studies the history of Changchun green space system planning molded City characteristics in Puppet Manchuria, 1980s and 21st century, in order to provide references for other cities in China from the aspects of shaping characteristic natural pattern, creating characteristic landscape style and building characteristic green space system.
\end{abstract}

Keywords: City characteristics, Urban green space system planning, Changchun

\section{INTRODUCTION}

Since the reform and opening up for more than 40 years, China has experienced a large-scale rapid urbanization and made remarkable achievements, which has promoted the sustained high-speed growth of China's economy and the continuous improvement of people's living standards. By 2019, China's urbanization rate has reached $60 \%$. However, in the context of rapid urbanization, the problem of "all cities with the same features" and "characteristic crisis" in China has become increasingly prominent. City characteristics are not only an important carrier to upgrade the city quality and inherit city culture, but also an grasp of driving urban development[1], therefore the protection and molding city characteristics has become the key work of urban planning and construction.

As an important part of a city, Urban Greenland plays an irreplaceable role in the molding and strengthening of the overall image of a city, and in the construction of a city with profound cultural heritage and distinctive image characteristics. Urban Greenland accounts for a large proportion of urban land, which makes green space become one of the decisive factors affecting the urban landscape. In terms of space construction, a good green space system can guide urban planning, limit the extensive development of the city, divide and protect the characteristics of each group of the city; in terms of image construction, as a city green space with its own characteristics, it is composed of strips, blocks and other distribution forms, and then becomes the symbol of the city. [2]

Changchun is a national historic city, it is also an important and complete demonstration of the scientific concept and comprehensive practice of modern urban planning in China. It has a grand urban space dominated by squares and radiated by axes. It was once more advanced than Tokyo in Asia. Changchun City has a high percentage of greenery coverage, and the formation of an organic overall structure, fully reflects the unique landscape characteristics of green space system. It can be said that Changchun City has a unique representation in urban green space system planning molds city characteristics. This paper, through the research of its history in different periods, hopes to provide some reference about the future green space construction and urban characteristics shaping for Changchun and other related cities. 


\section{CITY CHARACTERISTICS AND URBAN GREEN SPACE SYSTEM PLANNING}

\subsection{Connotation and elements of city characteristics}

City characteristics are the comprehensive embodiment and positive reflection of the characteristics of urban material form, social culture and economic characteristics, which are recognized by the public. [3] City characteristics are the image characteristics and image beauty displayed by material space under the premise of differences, and the local temperament transmitted by human activities. Natural environment and regional culture are the cornerstones of city characteristics; the urban function based on urban physical space, urban style and industrial development is the external material manifestation of urban internal characteristics.[4] The composition of urban characteristics includes natural factors and artificial factors (as shown in Table 1). Only when the two factors complement each other, the unique characteristics and temperament formed in city.

Table 1. Elements of urban characteristics

\begin{tabular}{|l|l|l|}
\hline \multicolumn{1}{|l|}{ Element classification } & Elements of city characteristics & \multicolumn{1}{|c|}{ city characteristic resources } \\
\hline \multirow{2}{*}{ 1. Natural factors } & (1) Natural conditions & $\begin{array}{l}\text { Climate characteristics, ecological characteristics, } \\
\text { tree cover, pastoral scenery, natural relics, etc }\end{array}$ \\
\cline { 2 - 3 } & (2) Geographical environment & $\begin{array}{l}\text { Geographical location, geological landform and } \\
\text { river system }\end{array}$ \\
\hline \multirow{2}{*}{ 2. Artificial factors } & (1) Human history & $\begin{array}{l}\text { Historical sites, revolutionary historical sites, } \\
\text { cultural relics, folk customs and traditional culture } \\
\end{array}$ \\
\cline { 2 - 3 } & (2) Cityscape & $\begin{array}{l}\text { Urban space form, architectural style, urban sketch, } \\
\text { urban street, square, plant landscape }\end{array}$ \\
\cline { 2 - 3 } & (3) Space industry & $\begin{array}{l}\text { Industrial structure, economic characteristics, } \\
\text { leisure service and urban nature }\end{array}$ \\
\hline
\end{tabular}

\subsection{The path of urban green space system planning molds city characteristics}

\subsubsection{Combing the context of urban natural environment, exploring the characteristics of urban geography}

The difference of urban location, terrain and natural environment creates the uniqueness of urban environmental characteristics, and also provides conditions for the shaping of urban characteristics. Urban green space system planning must give full play to the characteristics of natural resources, fully comb the existing lakes, rivers, mountains and other natural environment context of the city, according to the different natural environment conditions of the city, excavate the urban geographical characteristics, and integrate them into the urban planning, so that the natural resources play a fundamental role in the process of molding city characteristics.

\subsubsection{Respect the historical and cultural resources of the city and shape the cultural characteristics of the city}

The unique history and culture is the solidest part of a city, which constitutes the soul and spirit of a city. Therefore, in the process of urban green space system planning, we should pay attention to the excavation of urban historical and cultural resources, and embody the characteristic cultural symbols and elements in the construction of green space system.

\subsubsection{Strengthen the urban ecological pattern and construct the characteristics of artificial environment}

On the basis of fully analyzing the natural characteristics of the city, it is important to construct the urban spatial structure guided by the urban green space system structure. Taking urban green space system as a link, natural landscape pattern and public open space are integrated into the urban spatial structure, providing citizens with a good environment for recreation, and constructing the characteristics of urban artificial environment.

\section{HISTORICAL ORIGIN OF CHANGCHUN GREEN SPACE SYSTEM PLANNING MOLDS CITY CHARACTERISTICS}

\subsection{Changchun Green Space System Planning in Puppet Manchuria Period}

After Japan occupied Northeast China, it designated Changchun as the capital of Manchuria in 1932, which was renamed "Xin jing". The urban planning of Xinjing, in the sight of shaping urban ecological environment and 
creating transparent urban space, comprehensively used the most advanced urban planning theories in the west at that time, such as "Garden City", "Urban Beautification" and "Neighbourhood unit", It makes great changes in the urban form of Changchun.

\subsubsection{General layout of urban green space system planning}

With the goal of "Building Bright and Moist City ", the puppet Manchu "Xinjing" has laid out a large number of radial and circular green spaces, which are composed of green belts along the Yitong River and on both sides of the outside ring roads. Meanwhile, it adopts the form of centralized layout, and uses the tributaries of the Yitong River and low-lying terrain to lay out large and medium-sized parks. The whole city has planned six parks represented by Nanhu Park are connected by avenue trees. Ring green space, belt green space, wedge green space and point green space constitute an organic urban green space system. (as shown in Figure 1)

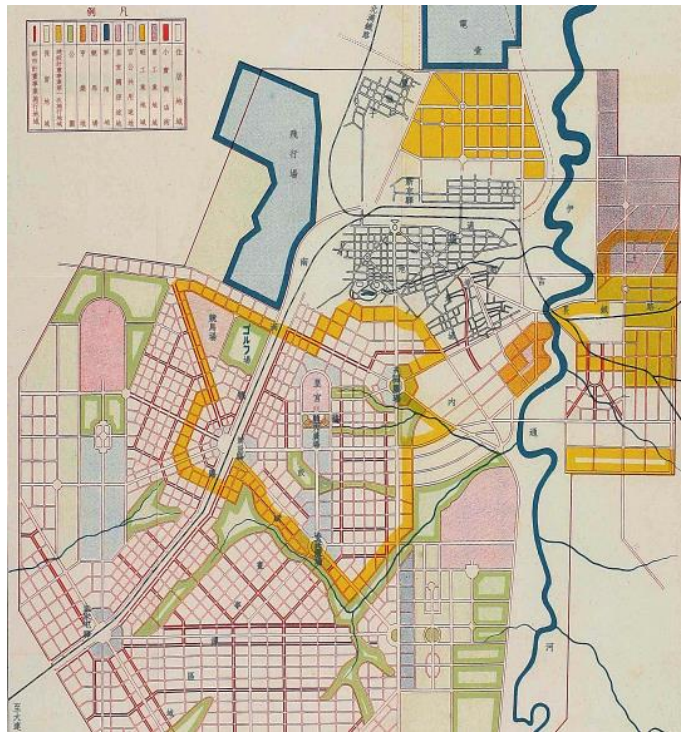

Figure 1. Urban green space system in Xinjing planning in 1932

\subsubsection{Characteristics of urban green space system construction}

\subsubsection{Creating flowing green space and embedding in urban block}

The urban planning of "Xinjing" attaches importance to the combination of water and green space. Taking the green space of Yitong River as the composition center, the pool formed by the low-lying land in the city is connected with Yitong River and planned as public park. At the same time, The connection of the water system between the parks is strengthened, the urban green belt along Yitong River and ring roads are planned, and the important landscape nodes are strengthened to make the public park. The ecological benefits and recreational functions of forest and green space can be fully developed.

"Xinjing" takes the square as the core in the layout of road network. For example, Datong square is 300 meters in diameter, which is equivalent to the park in the center of the city. From this kind of square, a number of boulevards are built, and wedge-shaped green space is embedded into the city block. The residential area forms a pattern of interval layout, which is convenient for residents to enjoy the public park quickly.

\subsubsection{Increasing the green space area and improving urban environment}

The urban green space construction of "Xinjing" is very effective. The urban green space area of the final planning and implementation is as high as 10.8 square kilometers, accounting for $12 \%$ of the land area of "Xinjing", and the per capita green space area is 31.3 square meters. Far beyond the level of Japan at that time, and even comparable with some developed cities in Europe and the United States. In the urban area, many green belts are built along the river. Native tree species such as poplar, willow, elm and locust grow inside and outside the dykes on both sides of the river. Such a rich reserve of plants and the "blue-green" structure of water and green blend, light and moisten the ecological environment of the city.

\subsection{Changchun Green space system planning in 1980s}

After the 1980s, influenced by the reform and opening up, Changchun gradually formed the urban circle structure with Renmin Square as the center. A large number of industrial land, residential land, commercial land and other different urban functional land gathered and developed in the city, which greatly changed the nature of urban using land. The original public green space cannot meet the needs of people, in order to maintain a good overall urban green environment and enrich the living environment space of the people, the green space planning of Changchun City makes full use of the original water system and green space system pattern, and increases the construction of point green space in the residential land and industrial land, with the green belt along the street and lake as the line, the green space in large parks and scenic spots as the surface, and the green space in Changchun City as the point line. In this period, the green space construction fully continued the tradition of using lake, river, terrain and other natural ecological environment elements and relying on the urban space texture. The green belt around the city and the green belt of water system were strengthened, and a "transparent, sparse, atmospheric, open" city characteristics were created. 


\subsection{Changchun Green space system planning after the 21st century}

After entering the 21st century, Changchun City continues to optimize the structure of urban green space system, strengthen the construction of green belt around the city, water system green space, ecological corridor and so on. In 2004, Changchun City Master Plan (20042020) proposed that the green space construction should form the layout form of "one vein", "one chain", "one ring", "multiple parks" and "line network", and build a multi-level, multi-functional and public park system.

In recent years, with the continuous promotion of ecological civilization construction, the scope of urban green space construction has been expanded to the city level, and more attention has been paid to the green space system research under the regional level environment. Focusing on the construction of landscape and famous scenery, forests, wetlands, country parks, the livable urban green space environment of "green wedge into the city, flowing green through the city" has been constructed. In the city, taking the river system as the skeleton, the green network of circular water system is constructed. Through the construction of green belt of tributary water system and urban road, the "green patches" of main parks and green spaces in the city are linked to form a unique ecological space system of urban green space network. (as shown in Figure 2)

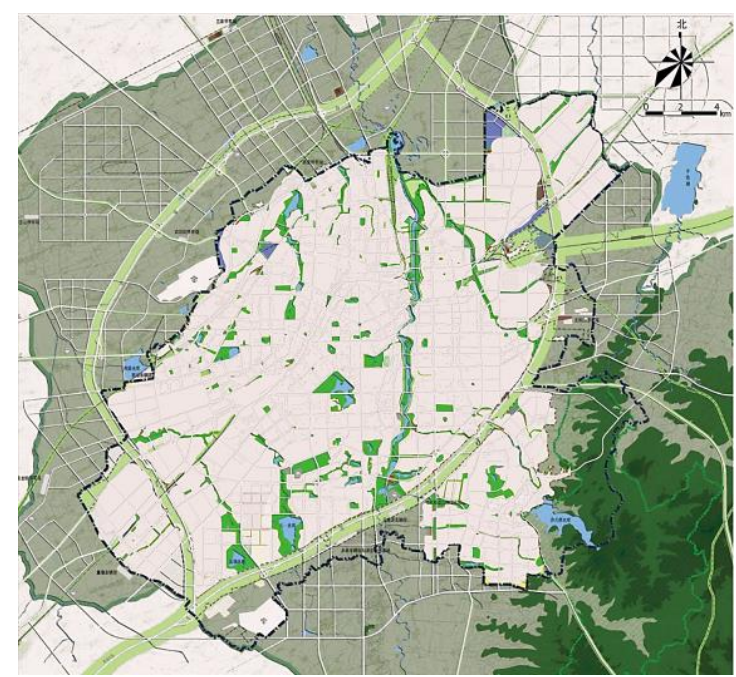

Figure 2. Changchun urban green space system planning from 2011 to 2020

\section{THINKING AND ENLIGHTENMENT TO URBAN GREEN SPACE SYSTEM PLANNING IN CHINA}

\subsection{Excavate the natural context and geographical characteristics, and shape the natural pattern with characteristics}

Changchun is a famous forest city in China. Yitong River passes through the city. The urban green space construction of Changchun always respects the natural context and geographical characteristics of "flowing green forest city", and attaches importance to the shaping of natural landscape pattern on a large scale. In the central city, through the construction of "flowing green space", the flowing green space connects the natural water. Where there is water, there is green space, and where there is green space, there must be water. Realize the excavating and molding characteristics in the natural environment.

\subsection{Respect the urban texture and historical context, molding featured urban landscape.}

"Wide roads, four rows of trees, round squares and small villas" is the impression of old Changchun. It has a rare urban pattern of modern western city management concept in China. The construction of Greenland in Changchun relies on the characteristic urban texture and historical culture, To create the axis of key cities, landscape corridor and characteristic style experience area, and form an orderly urban open space sequence, creating a landscape full of "Chinese and western city charm".

\subsection{Coordinate regional Greenland and urban Greenland, constructing characteristic green space system}

In accordance with the concept of "regional security, unblock near area, strong contact in urban ", the peripheral regional ecosystem integrated into the city in Changchun through the construction of urban country park and wedge-shaped passage green space, through the implementation of the "wedge corridor" and "big park construction strategy", constructing and optimizing the urban characteristics. The integrated development of regional green space and urban green space was realized.

\section{CONCLUSION}

Urban green space system planning is an important aspect of molding city characteristics. Changchun is a pioneer explorer in China, providing typical cases and practice samples for other cities. This study providing reference for Changchun and other cities in the future through analyzing the positive role of Changchun urban green space system planning molding city characteristics in various historical periods, realizing the Harmonious existenc between human and nature, and molding featured urban landscape.

\section{REFERENCES}

[1] Zhang Jia, Xiang Bing jun. Analysis on the positive role of city characteristic space in urban development [J]. Urban planning, 2013 (03): 17-20 
[2] Wang Hao, Xu Ying. Characteristics of urban green space system planning and layout[J]. Chinese garden, 2006, 22 (6)

[3] Shen Lei, Zhao Guoyu, Yao Ying. Nature, history, and myself: the question of shaping urban characteristics in the context of diversification $[\mathrm{J}]$. Urban planning, 2006 (03): 85-88

[4] Wang Hao. Urban green space system planning wolding city characteristics $[\mathrm{J}]$. Chinese garden, 2007, 23 (9): 90-94 